\title{
Design and the Creation of an Interactive Academic Space
}

\author{
Cristina Portugal \\ PUC Rio, Brazil \\ Av General Felicissimo Cardoso \\ 835, b2 701. Barra da Tijuca. \\ Rio de Janeiro, RJ. CEP 22631-360, Brazil \\ crisportugal@gmail.com
}

\author{
Natália Brunnet \\ PUC Rio, Brazil \\ Rua Leopoldo Miguez \\ 166, 601. Copacabana. \\ Rio de Janeiro RJ, CEP 22060-020, Brazil \\ nataliabrunnet@gmail.com
}

\begin{abstract}
This paper discusses a research project entitled "Design and contemporary digital technologies in education" which was awarded in 2014 by the Call Notice: MCTI / CNPQ / Universal. The study arose from the experience gained by the research work developed during the post-doctorates undertaken in the Graduate Program in Design and it resulted in two books: one in print and the other digital, both with the same title "Design, Education and Technology". This study aims to create an academic space in the form of an interactive hypermedia platform, directed to deepening of reflections, discussions and practical conceptual design and design activity, aiming to help the spread of knowledge, technological development and innovation in the process of teaching and learning design. This paper will present the concept of the interactive hypermedia platform that is being developed to assist the process of teaching-learning of scientific research. After the creation of the prototype, it will be tested and validated with the teachers of the University where the project is being developed. The discussions that will be undertaken will rely on the methodology, the reflections and the challenges for the development of the project.
\end{abstract}

Design. Interdisciplinarity. Technology. Interaction. Education.

\section{INTRODUCTION}

This paper discusses a research project called "Design and contemporaneous digital technologies in learning" which was contemplated in 2014, by Call for Proposals: MCTI/CNPQ/Universal14/2014, by the Brazilian funding agency for research. The study was born from the experience gathered by Prof. PhD. Cristina Portugal during the research developed in her postdoctoral internship that resulted in two books, one printed, and other digital, both with the same title "Design, Education and Technology".

This project comes from the knowledge generated by the research started during the postdoctoral. It is also an unfolding of the research regarding the involvement of a new language, new "projectual" elements and new relationships between teachers and students by means of different possibilities brought by contemporaneous digital technologies.

The theme guiding these investigations starts from the following question: if the teaching and the formation in design do not enable access, involvement and knowledge of the digital technologies in its primordial phase, how can we expect that professionals and researchers will develop studies as well as interdisciplinary and innovative projects for society?

Today, a large amount and diversity of platforms/sites is available, storing and sharing scientific publications. However, there is still a lack of researches setting guidelines for creating a network of connections between authors and fields, enabling dialogical processes between specialists from several knowledge areas, aware that the characteristics brought by contemporaneous digital technologies create a new way of conceiving and producing design. This study aims to create solutions to reduce this problem and to proportionate interdisciplinary theoretical knowledge that support discussions about the interrelationship between the study methodology, scientific methodology and projectual methodology of design considering "interdisciplinarity, as an inherent and essential condition for the practice of design" (Bonfim 1997).

With this study, it is intended to create an academic interactive space directed to deepening reflections, 
discussions and practices of the conceptual and projectual activity of design, aiming the concepts of the new time of interactivity, connectivity, non-linear navigability, in order to help the propagation of knowledge, technological development and innovation in the teaching-learning process of design.

Among results expected for this research are the intentions of fulfilling/reaching the following research objectives: Investigating the several relationships of design regarding contemporaneous digital technologies and the interaction of its praxis with Education and with the society where it is inserted. By achieving this objective, it is expected to promote the exercise of reflection, debate and criticism, propitiating to the professional a broad view of the inter-relationship between the teaching, scientific and conceptual methodologies of design. Preparing one interactive hypermedia system available online, gathering the main reflections developed during the research, providing their results for the academy as well as for society. Allowing the free access of teachers and students to the interactive hypermedia platform resulting from the developed research to be used in researches, disciplines, courses and classes, among other activities.

This paper will present, in general lines, the eBook used as the base for the development of this study and the concept of the teaching-learning platform being produced. Discussions that will be undertaken will discuss about the methodology, reflections and challenges discovered for developing the project. It will also present a research of similars, where the lack of studies about this type of platform will be evidenced.

\section{WHY THIS PROJECT?}

This research project, being an unfolding of the previously mentioned e-book, aims to provide strategies that collaborate for building new models, new approaches and interdisciplinary processes constituted by the inter-relationship between the teaching, scientific and projectual methodologies of design in contemporaneity.

The proposal of making available a space for reflection about characteristics and possibilities of the inter-relationship of the teaching, scientific and projectual methodologies of design is opportune, because Bonsiepe (2011) warns that the teaching of project in design was never able of matching the standards of scientific teaching. He also explains that there is difficulty in "incorporating the formation of projectual competence in academic structures", where "traditions and criterions of scientific excellence differ fundamentally from the traditions and criterions of projectual disciplines" (Bonsiepe 2011).

\section{According to Bomfim (1997):}

Design, by means of its praxis, would be the conciliatory or intervenor link between specialists from several areas. Interdisciplinarity as an inherent and essential condition to the practice of design, would dispense the constitution of another theory, that, after all, would be unfeasible, because its field of knowledge would know no frontiers.

Still according to the author:

A Theory of Design would not be the conquer of a single person, because transdisciplinarity is not the domain of one individual - it will be formed and developed by dialogical processes between the main participants involved in the different design situations, including the users themselves. This process requires, first of all, the will and humility to admit that there are different accumulated experiences, emotions, passions, idiosyncrasies and, mainly, the unknown.

Thus, the research project aims to create a hypermedia interactive system that provides theoretical contents and practices about the interrelationship between the teaching, scientific and projectual methodologies of design, considering possibilities made available by information and communication technologies.

From the analysis of several digital platforms comprising scientific periodicals, academic publications, processes of projectual results and social networks disseminating $\mathrm{CVs}$ and corporate profiles, a lack of integration between contents from different areas and of an intuitive search to help researchers, teachers and students was observed.

The idea of providing a platform emerged, therefore, from the need of creating an academic interactive space to visualise and make tangible interdisciplinary studies directed at deepening reflections, discussions and practices of conceptual and projectual activities of design. As mentioned before, it aims at the concepts and characteristics of interactivity, connectivity, navigability, technological development and innovation in the field of design as well as in related fields.

The project, object of this study, is in prototyping phase. After the creation of the prototype, it will be tested and validated with the teachers of the institution where this project is being developed. 


\section{RESEARCH ABOUT SIMILAR SITES AND TECHNOLOGY}

The research about similar sites and technology was split into three categories: platforms or sites storing and sharing scientific publications; platforms or sites optimising the visualisation of data; applications with functionalities similar to the ones of this research.

For each one of them several examples where collected. However, for this paper a few ones, more accordingly with the research project proposal, were selected.

\subsection{Platforms/sites storing and sharing scientific publications}

\subsubsection{International Scientific Publications}

An online collection of scientific magazines with open access, published by Info Invest Ltd. It has a policy of free access and makes available full texts of papers from its journals, for free. This enables to reach a larger public, increasing the citation rate in scientific works.

It has more than 20 years of experience in this line of publishing, with hundreds of papers published by scientists from over 30 countries. Currently, seven scientific journals are published about: Educational Alternatives; Language, People and Society; Media and Mass Communication; Agriculture and Alimentation; Ecology and Security; Materials, Methods and Technologies; Economy and Business.

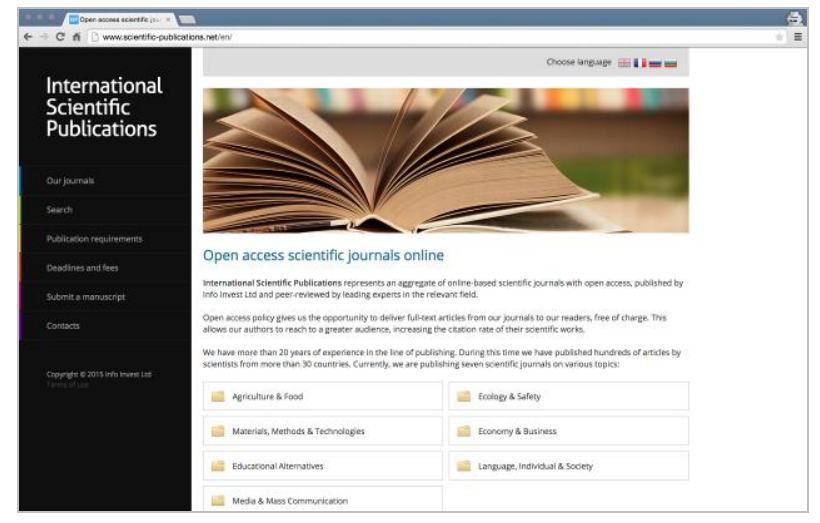

Figure 1: Site of International Scientific Publications (http://www.scientific-publications.net/en)

\subsection{Platform/site optimising data visualisation}

\subsubsection{Thinkmap}

Thinkmap's Software Development Kit (SDK) is a licensed tool that allows incorporating technology of data visualisation into web applications. Its applications allow users to visualise complex information that traditional interfaces are not able make available. It is a light visualisation component and based in the browser, allowing an interactive exploration.

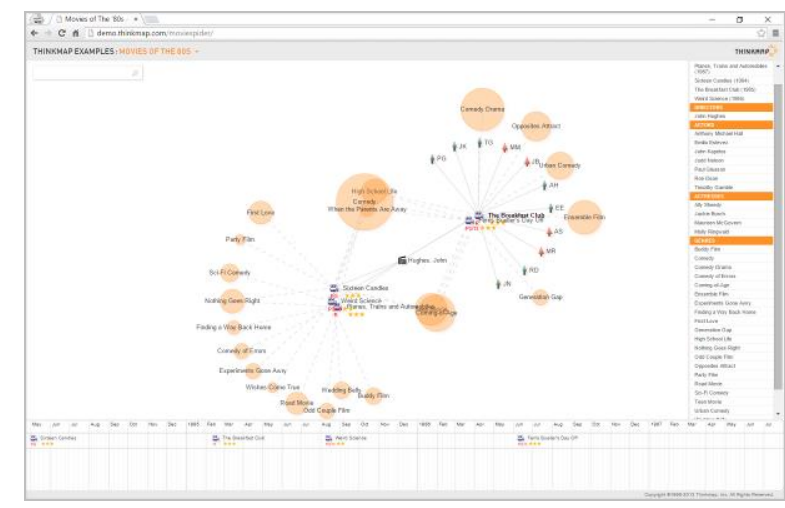

Figure 2: Example of applying Thinkmap SDK to visualise data from pictures from the 1980s (http://demo.thinkmap.com/moviespider).

One of the many applications created with Thinkmap is the Visual Thesaurus, a dictionary that creates word maps with their respective meanings, connected with related words. Its interface encourages exploration and learning.

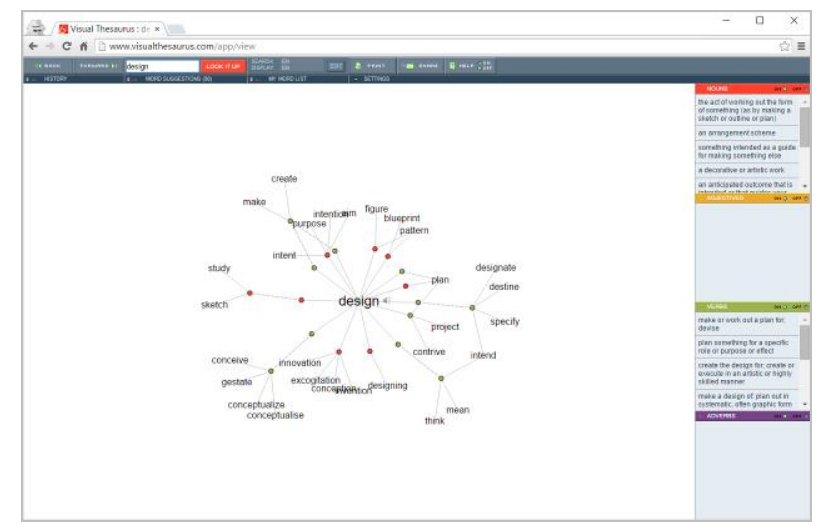

Figure 3: Interface of Visual Thesaurus (http://www.visualthesaurus.com/app/view).

\subsection{Applications with functionalities similar to the ones of this research}

\subsubsection{University of Applied Sciences - Zurich}

The application of exploratory network from the University of Applied Sciences - Zurich, links the different competencies of investigation about energy available in the institutes of the University. Competences are grouped in topics and subtopics, being possible to focus on details. 


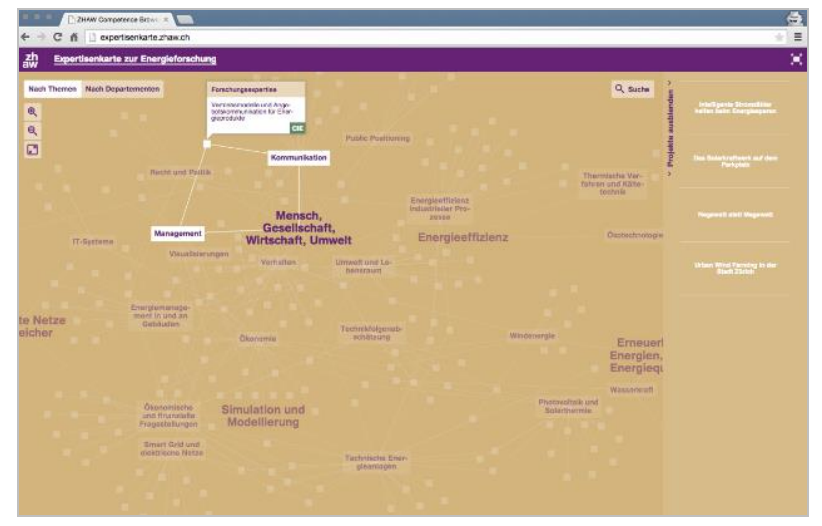

Figure 4: Site of the University of Applied Sciences Zurich (expertisenkarte.zhaw.ch).

\section{DETAILING AND DELIMITATING THE RESEARCH}

This project's prototype is being developed for a specific University, which will serve as a pilot. The goal is mapping and registering the areas of knowledge and its faculty, as well as their production, to contribute for research and studies in an interdisciplinary way.

The outcome expected is to provide an environment in the form of a digital platform for researchers, academics, professionals and students. The platform will allow the creation of a network connection between authors and areas of the pilot University and it will enable dialogic processes between experts from various fields of knowledge.

For delimitating the research project, in order to begin the creation of the platform's prototype, three fields were selected: Design, Interdisciplinarity and Society. Initially, each one of them was subdivided into three areas as follows: the field of Design into Theory of Design, Digital Design, and Graphic Design; the field of Interdisciplinarity into Technology, Education and Philosophy and the field of Society into Culture, Sustainability and Inclusion/Citizenship. One of the criteria established for creating a first prototype was that an author in the field of design must be associated with an interdisciplinary field and with an application to society. And, as an example for each one of the areas, an author nationally and internationally recognised by its competence was selected.

According to Portugal (2013), design, as an interdisciplinary activity, works with several areas of knowledge, enabling an wide view during the development of projects that solve diverse problems and fulfil different necessities. As an activity of multiple approaches, design acts with different emphases in order to maximise the objectives of the project.

In the words of Bonsiepe (2011), knowledge considered as accumulated experiences must be communicated and shared, with presentation of information/knowledge being a central task of design. This idea is consistent with the objectives of this research proposal, in the interactive system being proposed, besides also containing papers, studies, recent researches and information about authors approaching the themes of design, interdisciplinarity and society, with an special focus on their connections, aiming to deepen the relationship and exchange of knowledge with those areas, generating future studies and innovative relationships.

Thus, it will be possible to search more intuitively, for instance from visually represented key-words, considering that the synthesis of each author's work contributes for the development and integration of the three mentioned areas.

With the project unfolding, after the platform prototype is created, the objective is to expand it and to have the direct contribution of authors updating the content, generating a live platform (semantic web) that may foster the teaching, education and propagation of authors which contribute for the advancement of the field of Design.

For the first prototype created for future tests, the areas of Design, Interdisciplinarity and Society were selected, as well as subthemes of each area. In the first studies, the classification by key-words was used for the prototype. However, other taxonomic studies are being investigated in order to potentiate the holistic characteristic of the transdisciplinary knowledge brought by the platform, such as:

(i) Key-words (classification of the current prototype): words manually placed to resume the subjects of works from the authors, like what is made in scientific publications and some social networks (Twitter, Instagram).

(ii) Words more used in the content, dynamically mapped by one script.

(iii) Metadata (semantic web/RDI).

\subsection{Start screen of the interactive search}

In this screen, the user may have a general overview and network vision about the themes, subthemes and authors. This information will be visually updated to the user every time that information is added in the database. This experimental way of searching and interacting with 
information, enables each user to create a route and to have an unique experience, discovering connections, authors and new subjects.

During the experience, the way of interacting may change according to the equipment used, when moving the mouse or by means of touch devices, to highlight the main fields of activity of that author in the network. Thus, besides exploring its work, the user will be able to explore other fields of knowledge and to know new authors, important for its researches and projects, creating new connections in its own work.

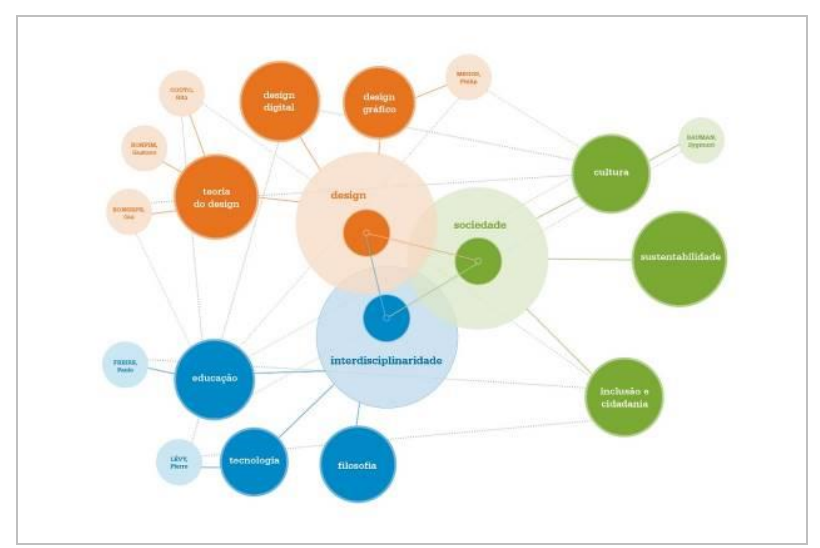

Figure 5: First prototype of the start screen of the interactive search, showing connections between themes and authors.

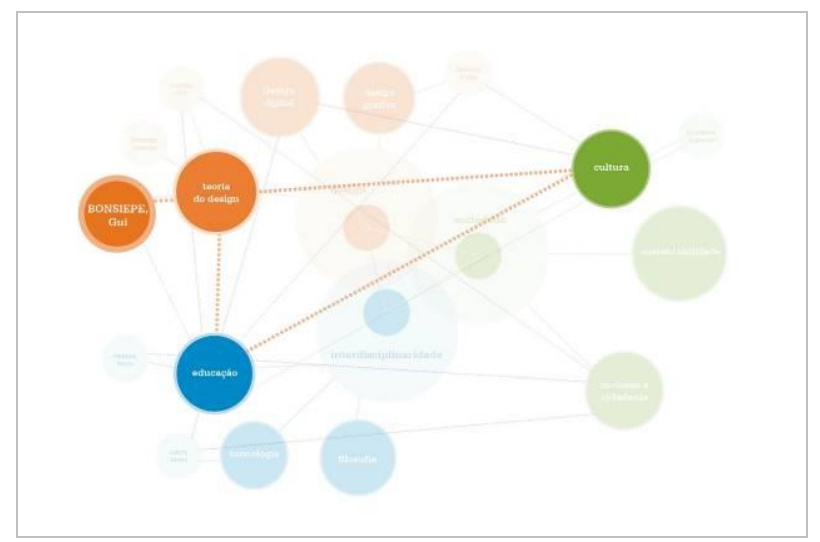

Figure 6: An example of the screen when moving the mouse over the name of author Gui Bonsiepe.

If the user chooses to click on the author, a screen with a summary sheet is opened. In this screen there is resumed information about the author and its publications. The objective of this summary sheet is to gather valid and verified information about that author for the researcher, as well as about trustable sources where its books and papers can be found. This organisation of information aims to accelerate the development process of researches and projects.

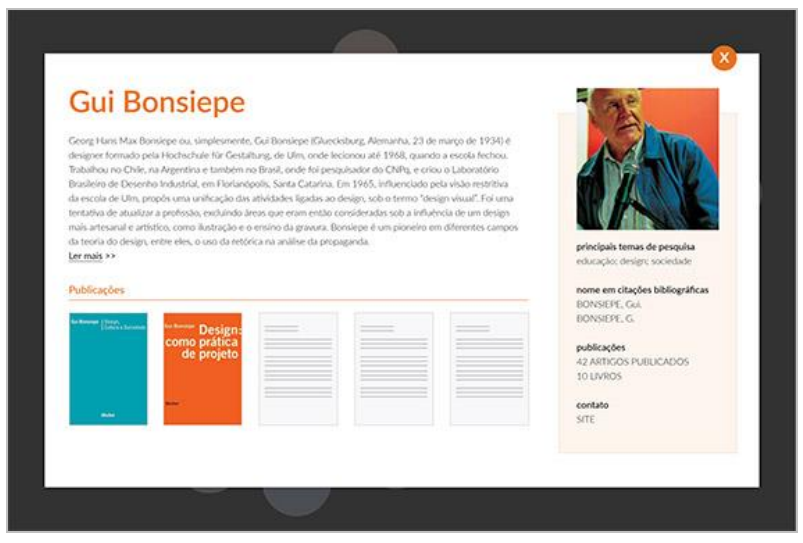

Figure 7: Screen with the summary sheet of the design author Gui Bonsiepe.

The three initially chosen areas, Design, Interdisciplinarity and Society, were identified by colours orange, blue and green, respectively.

Apart from allowing a visual organisation in the screen of the interactive search, the colours of each main field are also in the summary sheets of the authors, according to an overseeing based on the field that better includes its selected works.

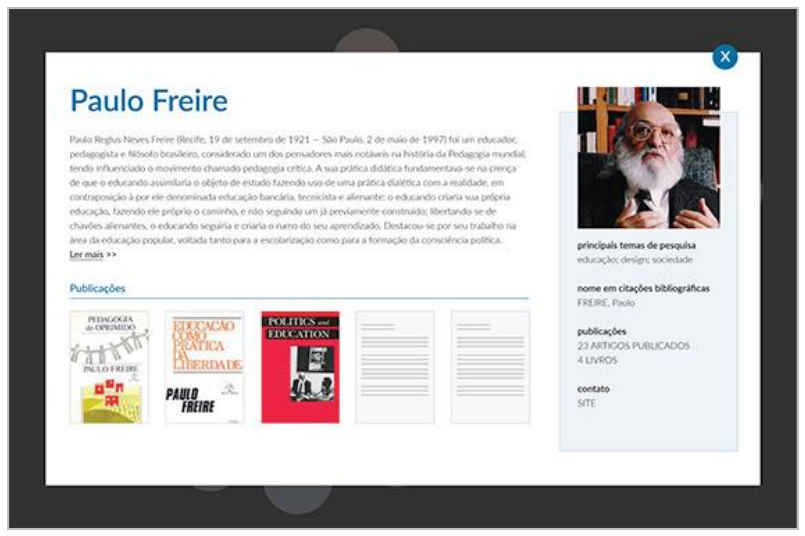

Figure 8: Example of a reference author in the area of Education: Paulo Freire. Education is a subtheme of Interdisciplinarity.

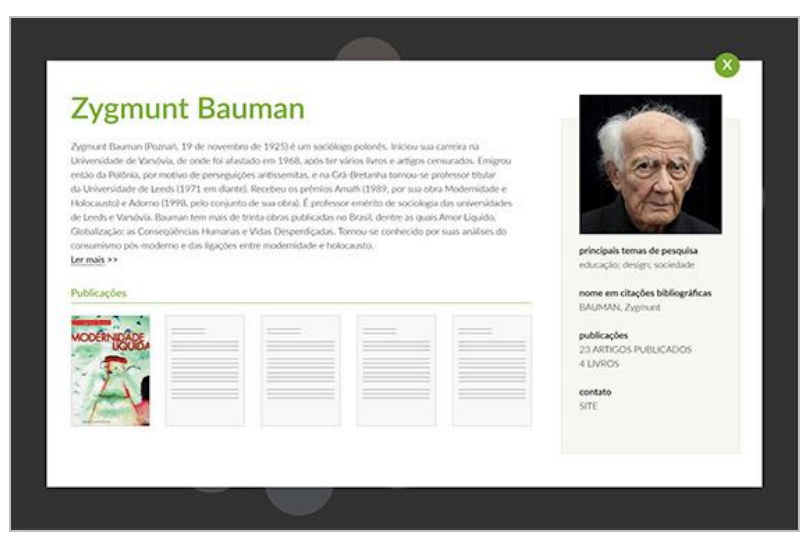

Figure 9: Summary sheet of Zygmunt Bauman, highlighting his works in the area of Society. 
By observing the first prototype, it was decided to keep the main areas of Design, Interdisciplinarity and Society for the second prototype. However, after analyzing the first model, the need of improving the concept and the interface of the project was observed.

Thus, new criteria were conceived and defined for choosing subareas, authors and also for creating connections between them. The objectives for defining those criteria were based in keeping the project concept along the feeding of content in the platform and to improve the experience that users will have when searching themes and authors related with their researches. So, both for the insertion as well as for the content search, the overall picture, the network vision and the routes of themes, subthemes and authors will be clearer. Thus, the criteria used for improving the concept were:

- Begin the web of information by relevant authors for the field of Design and then to connect them to the two other fields (Interdisciplinarity and Society).

- For the three fields no limit was defined regarding the number of subareas.
- For the fields of Interdisciplinarity and Society, a specific criterion was defined regarding the unfolding in subareas: they will happen from the theme of works to which authors previously defined in the field of Design may connect to.

Additionally, the possibility of improving the design of information from the interactive search was mentioned. In this case, the defined criteria were:

- Attribution of weight to the three main areas of the web, centralising and giving more visual weight to the field of Design.

- Redistribution of information.

- New layout for points marking the subareas.

- Insertion of icons, in order to visually enrich the project and to facilitate the understanding of information.

Comparing with the first prototype, new themes for the area of Design were added in this second model, in order to test the scalability capacity of the model with approximately the double of items. In consequence, new subareas were included in fields Interdisciplinarity and Society.

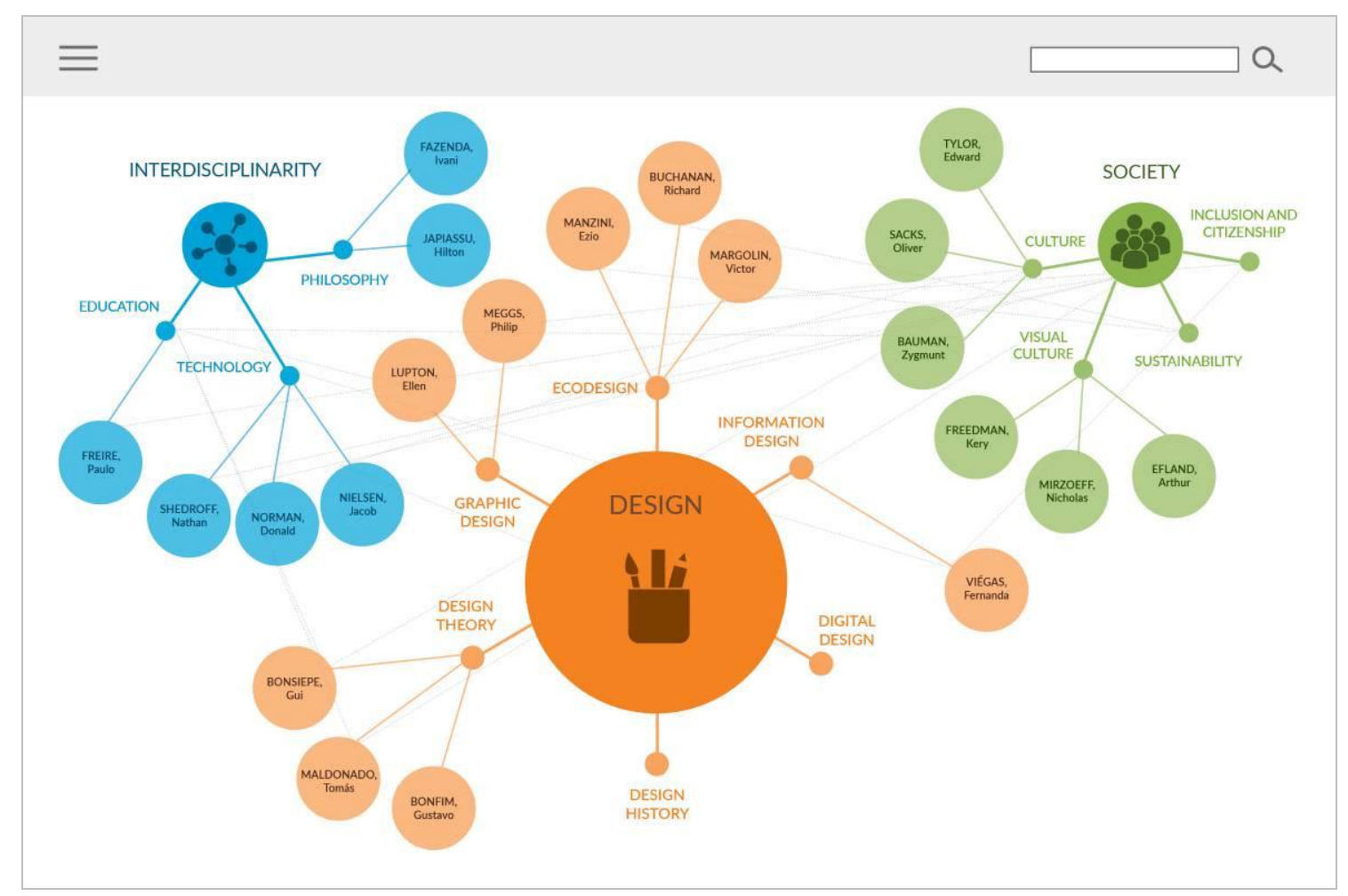

Figure 10: Second prototype of the interactive search screen, showing connections between themes and authors. 


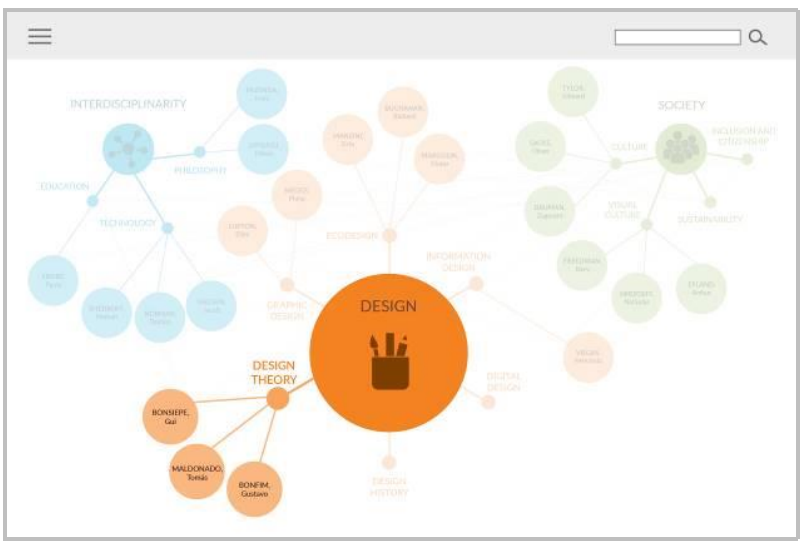

Figure 11: Second prototype of the interactive search screen, showing mouse over the subarea "Design Theory".

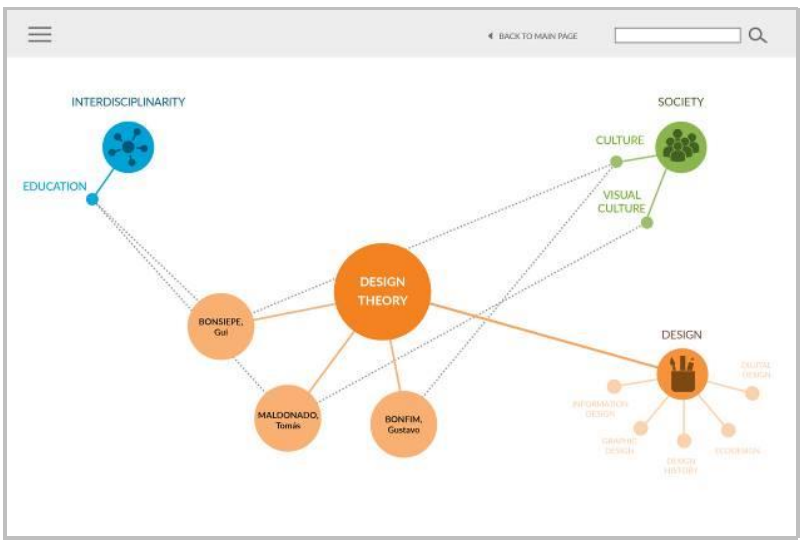

Figure 12: This is the screen layout after clicking on a subarea.

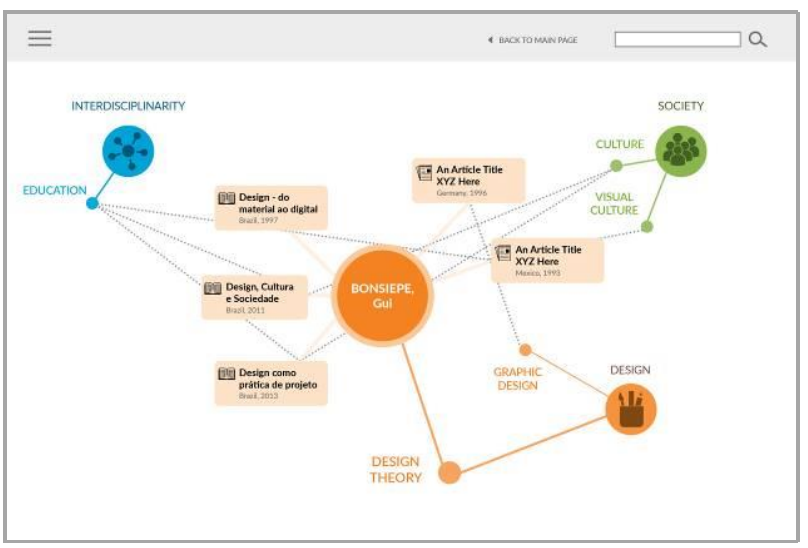

Figure 13: This is the screen layout after clicking on an author's name, showing his publications.

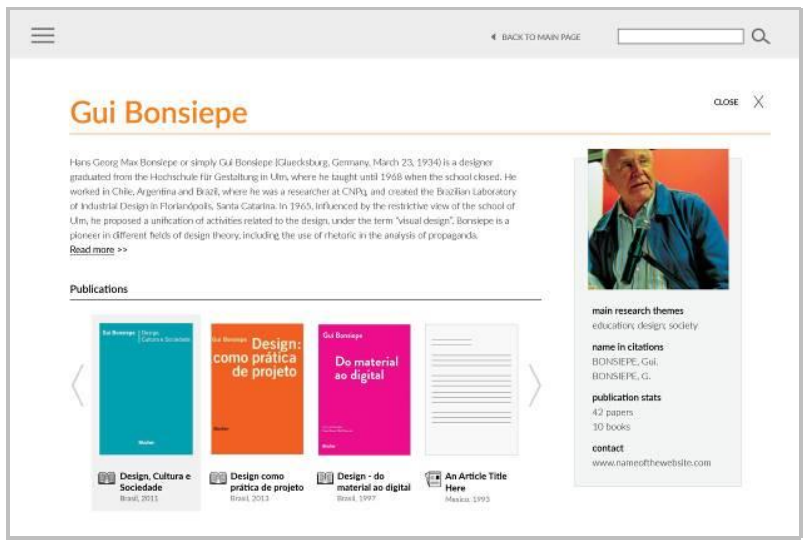

Figure 14: Screen with the summary sheet of the design author Gui Bonsiepe.

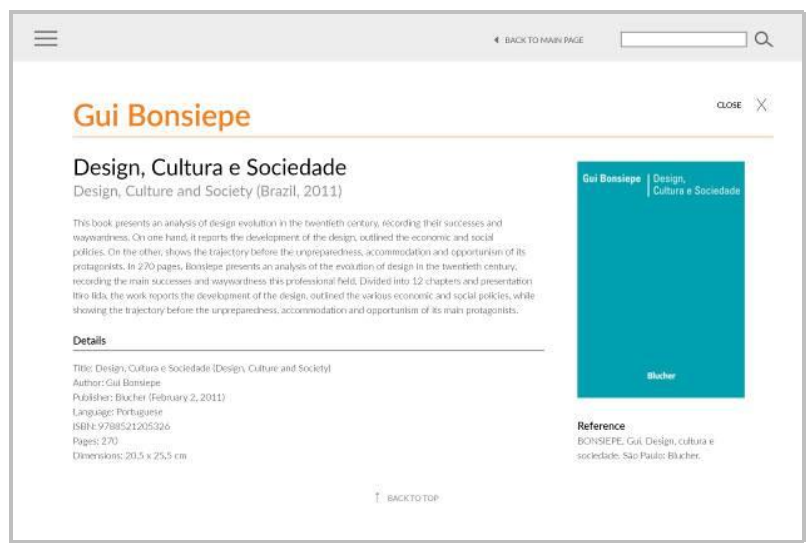

Figure 15: This is the screen layout after clicking on a specific publication.

\section{FINAL CONSIDERATIONS}

The research project presented in this paper starts from a reflection based on the ideas of Manzini (2004), when stating the need of thinking "design in a fluid world", in which products, services and information are combined and generate new ways of projecting, producing, consuming and using in an unprecedented manner, resulting from the articulation of a multiplicity of authors. The author states that, in order to act in this context, designers "must change their professional profile converting in operators acting inside a network, assuming the role of providers of the innovation process". By considering the possibility of sustainable solutions, the activity of design that drives the process of innovation should be facilitated by designers, instead of being directly performed by them (Manzini 2004). Manzini (2004) intensifies its ideas stating that the designer, from its creativity and communication abilities, may contribute to promote a high degree of active social participation.

We live in a time when the Internet, as well as the several equipments and technologies available to connect with it, enable the building of a new 
paradigm of generating knowledge and access to information.

\begin{abstract}
(...) despite the agility in changing systems and processes, we may perceive that the digital technologies, externalised and boosted four qualities of the human being: the curiosity, the creativity, the cooperation and the ludic experience. Interactivity being mentioned as one of the best openings for those questions and for the creative thinking (Moura 2003).
\end{abstract}

It is important to mention that the relationship with knowledge has changed and allowed a differentiate action of the user by means of the information and communication technologies.

\begin{abstract}
The interactive disposition enables the user to be actor and author, making communication not only the work of emission, but also the cocreation of the message itself and of communication. It allows participation understood as exchange of actions, control over events and modification of contents. The user may hear, read, record, return, go ahead, select, treat and send any type of message for any place. In short, interactivity allows surpassing the condition of passive spectator to the condition of operative subject (Silva 2012).
\end{abstract}

However Moran states:

(...) the process of changing will be slower than many people imagine (...) There is a large economic inequality, of access, maturity and motivation of people. Some are ready for change, many others not. It is hard to change acquired standards (management, attitude) of organisations, governments, professionals and society (Moran 2003).

In this sense, this study searches solutions by means of an environment that is easy to use and intuitive, since it considers that there are no platforms aimed at the field of design that can support the complexity involving the area as well as the several interdisciplinary connections contemplating social changes inherent to the contemporary world. For Portugal (2013), generally, there is also no adequate integration of the fields which are essential for this work. As an example, hypertext technologies, multimedia, social networks and tools for cooperative work demand a new design and a new way of relationship that privileges the acquisition of competencies and abilities for searching and selecting information and for building the knowledge on the available digital environments that are being used by teachers and students.

This study aims to create an environment, in the form of a digital platform, for researchers, academics, professionals and students, being able to create a connection network between authors and areas that allow dialogic processes between experts from several areas of knowledge. Thus, transmitting and sharing knowledge in the form of high quality empirical and theoretical research works about design focused on interdisciplinarity and that, returning Bomfim's words, understand "interdisciplinarity, as inherent and essential condition to the practice of design". (Bomfim 1997).

\section{REFERENCES}

Bomfim, G. A. (1997) Fundamentos de uma teoria transdisciplinar do design: morfologia dos objetos de uso e sistemas de comunicação. Estudos em Design, n.2, v.5, pp.27-41.

Bonsiepe, G. (2011) Design, Cultura e Sociedade. São Paulo: Edgar Blucher.

(1997) Design do material ao digital. Florianópolis: FIESC/IEL.

Gamba Jr, N. (2013) 4ํㅜ capa. In Portugal, C. Design, educação e tecnologia. Rio de Janeiro: Rio Books.

Manzini, E. (2004) El diseño como herramienta para la sostenabilidad medioambiental y social. In Macdonald, s. (org.) Design issues in Europe today. Barcelona: BEDA.

Moran, J. M. (2003) A educação que desejamos: novos desafios de como chegar lá. São Paulo: Papirus.

Moura, M. (2014) Interdisciplinaridades no Design Contemporâneo.

http://www.academia.edu/4880345 (retrieved 14 August 2014).

Portugal, C. (2013) Design, educação e tecnologia. Rio de Janeiro: Rio Books.

(2013) Design, educação e tecnologia (online): Rio de Janeiro: Rio Books. Available under: http://www.design-educacao-tecnologia.com (retrieved 27 April 2015).

(2015) Design education and hypermedia In The Value of Design Research 11th International European Academy of Design Conference: Paris Descartes University, Paris.

(2014) Hypermedia E-book as a Pedagogical Tool in a Graduation Course. International journal of modern education and computer science (IJMECS), v. 6, pp. 8-14.

Silva, M. (2003) Aula Interativa: A Educação Presencial e a Distância em Sintonia com a Era Digital e com a Cidadania.

http://www.saladeaulainterativa.pro.br/texto 0008.h tm (retrieved 28 August 2012). 